\title{
SIMULATION OF FSO SYSTEM OPERATION IN DIFFERENT ATMOSPHERIC CONDITIONS
}

\author{
Jelena Todorovici ${ }^{1 *}$, \\ Branimir Jakšić ${ }^{\text {, }}$ \\ Petar Spalević2, \\ Majid Alsadi2, \\ Ahmad Mohammed Salih ${ }^{2}$
}

${ }^{1}$ Faculty of Technical Sciences, University of Priština in Kosovska Mitrovica, Kosovska Mitrovica, Serbia

${ }^{2}$ Faculty of Informatics and Computing, Singidunum University,

Belgrade, Serbia
Correspondence:

Jelena Todorović

e-mail:

jelena.todorovic@pr.ac.rs

\begin{abstract}
:
In this paper, using simulation in the software OptiSystem 7.4, the FSO (Free Space Optical) system operating at wavelengths of $850 \mathrm{~nm}, 1315 \mathrm{~nm}$ and 1550 $\mathrm{nm}$ was observed. The influence of different levels of atmospheric turbulence and link distance on the signal transmission quality was investigated. The Q factor and BER (Bit Error Rate) were used as a measure of quality. The changes of the $\mathrm{Q}$ factor depending on the observed system parameters are graphically shown. Eye diagrams and signal spectrum are also given. The analysis of the results shows how the quality of the received signal changes due to different atmospheric phenomena at certain distances from the transmitter.
\end{abstract}

Keywords:

Free Space Optical - FSO, attenuation, atmospheric turbulence, Bit Error Rate - BER, Q factor.

\section{INTRODUCTION}

Wired optical networks are sometimes difficult to implement due to their complexity in installation and relatively expensive fiber technology. Therefore, they are not always a good solution, although they provide a wide range and high transmission speeds. FSO technology is a good alternative for short or medium distance transmission, especially for environments where wired optical network infrastructure is difficult to apply [1]. Compared to wired optical networks, the application of the FSO system is simpler, easier, faster and therefore cheaper. It also provides excellent data transmission security, high transmission speeds, as well as high bandwidth capability [2-5].

Beside to the various advantages provided by the FSO communication system, there are also various problems that lead to the degradation of the optical link and hinder its use. FSO systems are very vulnerable to atmospheric conditions. Since the signal propagates in free space, it is affected by atmospheric turbulence and pointing errors, which degrades system performance. Snow and rain have a significantly smaller impact on the transmission quality compared to atmospheric turbulence and fog [1,6-9]. 
Atmospheric turbulence has a strong impact on the signal being transmitted and on the wavelengths of the system. Atmospheric turbulence is caused by both spatial and temporal random fluctuations of the refractive index due to changes in temperature, pressure and wind along the path of optical propagation through the channel $[1,2]$. Due to unfavorable atmospheric conditions, beam spreading, image dancing, beam wander, scintillation and intensity fluctuation and signal phase can occur $[10,11]$. This affects the FSO system performance and leads to high values of the Bit Error Rate (BER), i.e. to small values of the quality factor ( $\mathrm{Q}$ factor) $[3,12,13]$.

The deterioration in the FSO system performance is also greatly affected by small changes in the position of the transmitter and receiver. Many factors, such as building sway, wind loads or thermal expansion, can cause a misalignment, leading to pointing errors and signal fading at the receiver. All these factors are essential when planning a FSO system and therefore must be considered $[6,14,15]$.

In this paper, the impact of weather conditions, i.e. atmospheric turbulence and link distance on the transmission quality in the FSO system is investigated. The Section 1 presents a system model that is analyzed in an OptiSystem environment. In the Section 2, the obtained simulation results for different wavelengths and distances between transmitter and receiver, as well as for attenuations caused by the impact of different atmospheric phenomena, are graphically presented and discussed. The Section 3 is the Conclusion.

\section{SYSTEM MODEL}

The system model used for the simulation in the software OptiSystem 7.4 [16] is given in Fig. 1. At the input of the observed system are Pseudo-Random Bit Sequence (PRBS) and NRZ (Non-Return to Zero) Pulse Generator that are fed together to the Mach-Zehnder Modulator. The binary sequence of pseudo-random bits generated in the PRBS Generator passes through the NRZ Pulse Generator where that bit sequence is converted into electrical pulses. The pulse thus obtained and the signal from the source modeled by the CW (Continuous-wave) Laser are modulated in a Mach-Zehnder Modulator. The output thus obtained is an optical signal of variable intensity in accordance with the input electrical signal. A modulated optical signal is fed to the input of the component representing the FSO channel, where attenuation values due to atmospheric influences can be entered. The Optical Receiver with Cutoff Frequency $=0.75$ * BitRate $\mathrm{Hz}$ is located on the receiving side, and a BER analyzer is connected to it, which is used to read the measured parameters.

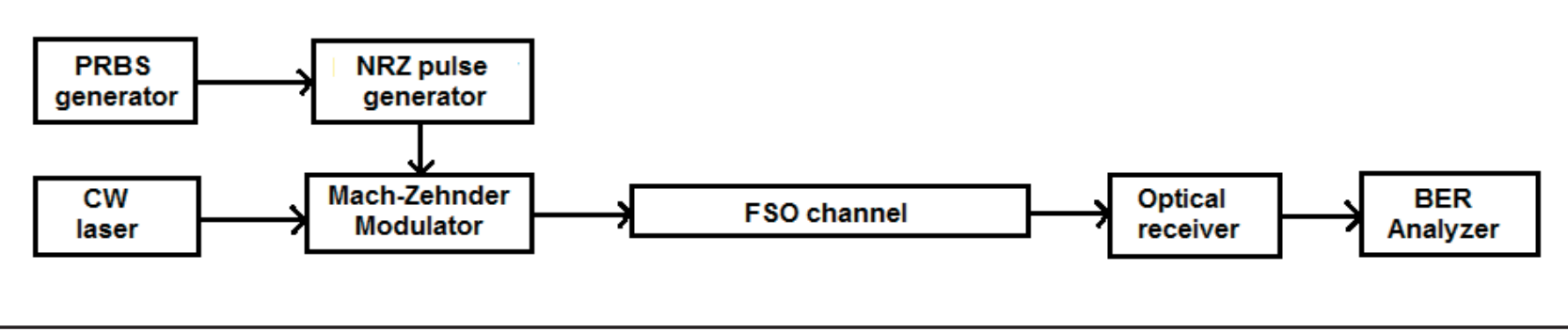

Fig. 1. Block diagram of the system model.

The system was simulated with a transmitter power of $10 \mathrm{~mW}$ and at wavelengths of $850 \mathrm{~nm}, 1315 \mathrm{~nm}$ and $1550 \mathrm{~nm}$. The transmitter and receivers aperture diameter are $5 \mathrm{~cm}$ and $7.5 \mathrm{~cm}$, respectively, while their losses are $1.8 \mathrm{~dB}$ each. The beam divergence is $2 \mathrm{mrad}$, while the other additional losses are $1 \mathrm{~dB}$.

The analysis was performed for different FSO link distances of $500 \mathrm{~m}, 1000 \mathrm{~m}, 1500 \mathrm{~m}$ and $2000 \mathrm{~m}$, as well as for attenuations from $0 \mathrm{~dB} / \mathrm{km}$ to $40 \mathrm{~dB} / \mathrm{km}$. Attenuation in this range is caused by the impact of various atmospheric phenomena such as clear weather, haze, rain, fog whose attenuations are given in Table $1[7,8]$.
Attenuations in case of clear weather or light haze can be classified as weak turbulence, fog, light rain and very light fog in the category of moderate turbulence, while moderate to heavy rain and fog belong to the category of strong turbulence. 
Table 1. ATTENUATION AT DIFFERENT ATMOSPHERIC PHENOMENA

\begin{tabular}{ll}
\hline Atmospheric phenomena & Attenuation $[\mathrm{dB} / \mathrm{km}]$ \\
\hline Very clear & $0.19-0.47$ \\
\hline Clear & $0.54-0.6$ \\
\hline Light haze & $1.1-2$ \\
\hline Haze & $3.1-4.6$ \\
\hline Light rain & 6.27 \\
\hline Moderate rain & 9.64 \\
\hline Heavy rain & 19.28 \\
\hline Light fog & $6.6-18.3$ \\
\hline Moderate fog & 28.9 \\
\hline Heavy fog & 75
\end{tabular}

\section{SIMULATION RESULTS}

Fig. 2, Fig. 3 and Fig. 4 show the behavior of the $\mathrm{Q}$ factor versus attenuations caused by different atmospheric phenomena and for different distance lengths between transmitter and receiver, at wavelengths of 850 $\mathrm{nm}, 1315 \mathrm{~nm}$ and $1550 \mathrm{~nm}$, respectively.

From the given figures it can be seen that the transmission is of high quality in clear weather, as well as when the haze is weaker or somewhat stronger, since the value of $\mathrm{Q}>5.5$ is necessary for quality transmission. In light and moderate rain, as well as light fog, quality transmission can be achieved at a maximum distance of $1000 \mathrm{~m}$ at a wavelength of $850 \mathrm{~nm}$. Under the same conditions at a wavelength of $1315 \mathrm{~nm}$, the transmission will be correct even at slightly longer distances than $1000 \mathrm{~m}$, while in the case when the wavelength is 1550 $\mathrm{nm}$, the transmission quality will be good up to $2000 \mathrm{~m}$.

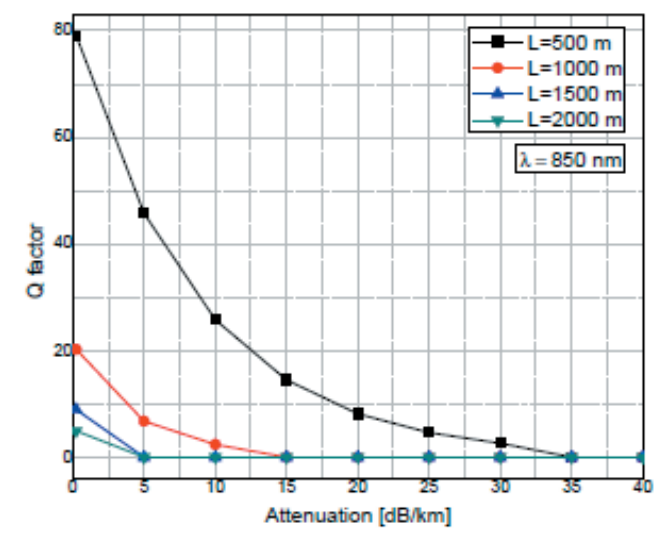

Fig. 2. Q factor for different FSO link distances at a wavelength of $\lambda=850 \mathrm{~nm}$.

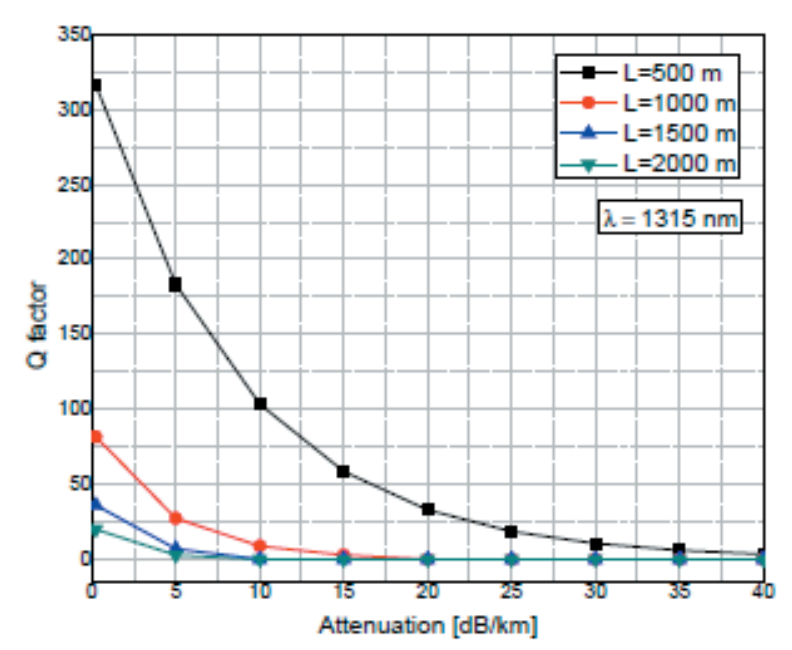

Fig. 3. Q factor for different FSO link distances at a wavelength of $\lambda=1315 \mathrm{~nm}$.

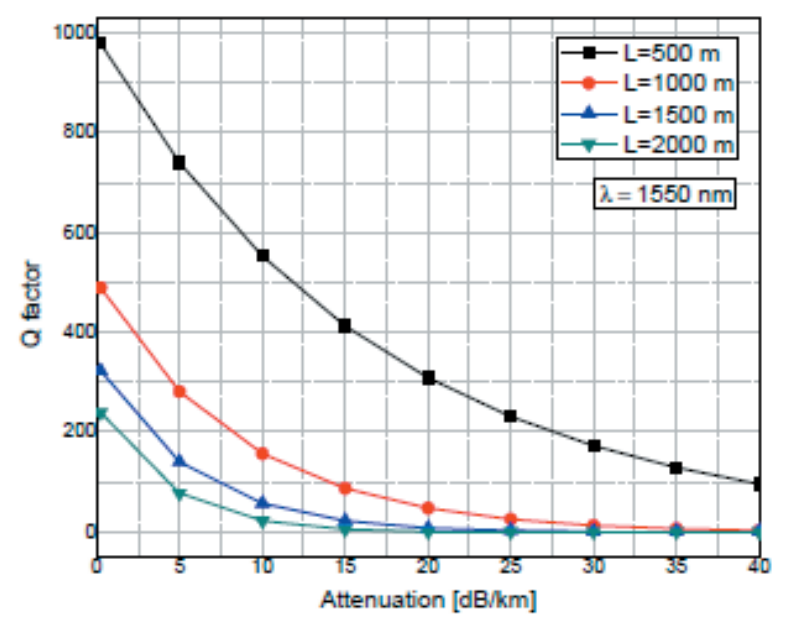

Fig. 4. Q factor for different FSO link distances at a wavelength of $\lambda=1550 \mathrm{~nm}$.

From Fig. 2 and Fig. 3 it can be seen that in worse atmospheric phenomena, quality signal transmission is impossible to achieve at distances greater than $500 \mathrm{~m}$. In order for this to be achieved, certain parameters of the system must be changed on the transmitting side, such as e.g. increasing the source power.

Based on the results shown in Fig. 4, it can be concluded that the FSO system has the best performance at a wavelength of $1550 \mathrm{~nm}$, where it is possible to achieve quality transmission over longer distances, at $1000 \mathrm{~m}$ in almost all weather conditions, while at longer distances it is achievable for attenuations up to $20 \mathrm{~dB} / \mathrm{km}$. Also, the decrease in $\mathrm{Q}$ factor is more pronounced at shorter distances. As the link distance increases, the decrease in the $\mathrm{Q}$ factor is less pronounced. 
Table 2 shows the BER values of the observed FSO system at wavelengths of $850 \mathrm{~nm}, 1315 \mathrm{~nm}$ and 1550 $\mathrm{nm}$ for different values of attenuation and link distances.

BER eye diagrams for link distances $\mathrm{L}=1000 \mathrm{~m}$ and $\mathrm{L}=2000 \mathrm{~m}$ and attenuation caused by moderate rain and moderate fog are given in Fig. 5 and Fig. 6, respectively. Closed lines represent sectors with BER values of $10^{-8}$ to $10^{-12}$. The eye opening corresponds to the change of the $\mathrm{Q}$ factor in Fig. 4. a)

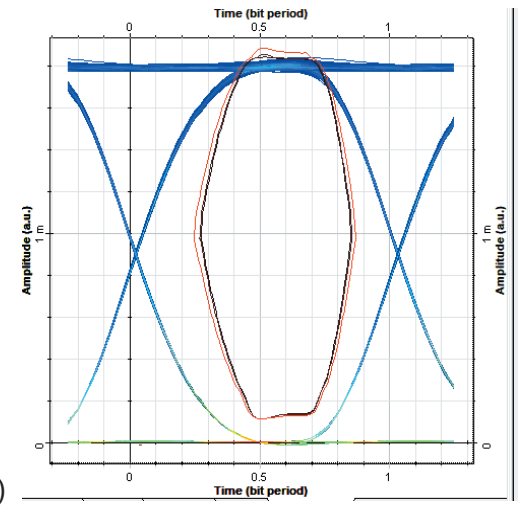

b)

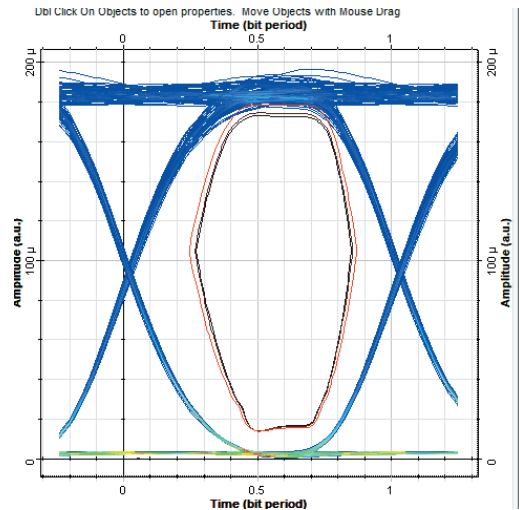

Fig. 5.Eye diagram of the received signal for the FSO link distance $\mathrm{L}=1000 \mathrm{~m}$ and attenuation caused by: a) moderate rain, b) moderate fog.

Table 2. BER PARAMETER VALUES FOR DIFFERENT FSO SYSTEM CONDITIONS.

\begin{tabular}{cccccccccc}
\hline \multirow{2}{*}{ Attenuation } & \multicolumn{3}{c}{$\mathrm{L}=1000 \mathrm{~m}$} & \multicolumn{3}{c}{$\mathrm{L}=1500 \mathrm{~m}$} & \multicolumn{3}{c}{$\mathrm{L}=2000 \mathrm{~m}$} \\
\cline { 2 - 10 } & $850 \mathrm{~nm}$ & $1315 \mathrm{~nm}$ & $1550 \mathrm{~nm}$ & $850 \mathrm{~nm}$ & $1315 \mathrm{~nm}$ & $1550 \mathrm{~nm}$ & $850 \mathrm{~nm}$ & $1315 \mathrm{~nm}$ & $1550 \mathrm{~nm}$ \\
\hline 0.23 & $1.659 \mathrm{e}-091$ & 0 & 0 & $2.449 \mathrm{e}-019$ & $5.905 \mathrm{e}-285$ & 0 & $4.019 \mathrm{e}-007$ & $1.344 \mathrm{e}-088$ & 0 \\
\hline 5 & $6.879 \mathrm{e}-012$ & $7.712 \mathrm{e}-165$ & 0 & 1 & $1.814 \mathrm{e}-012$ & 0 & 1 & 0.00246 & 0 \\
\hline 10 & 0.00840034 & $2.622 \mathrm{e}-018$ & 0 & 1 & 1 & 0 & 1 & 1 & $3.030 \mathrm{e}-107$ \\
\hline 15 & 1 & 0.002908 & 0 & 1 & 1 & $3.289 \mathrm{e}-106$ & 1 & 1 & $2.474 \mathrm{e}-007$ \\
\hline 20 & 1 & 1 & 0 & 1 & 1 & $4.156 \mathrm{e}-014$ & 1 & 1 & 1 \\
\hline 25 & 1 & 1 & $3.273 \mathrm{e}-136$ & 1 & 1 & 0.007398 & 1 & 1 & 1 \\
\hline 30 & 1 & 1 & $6.708 \mathrm{e}-036$ & 1 & 1 & 1 & 1 & 1 & 1 \\
\hline 35 & 1 & 1 & $2.582 \mathrm{e}-009$ & 1 & 1 & 1 & 1 & 1 & 1 \\
\hline 40 & 1 & 1 & 0.006945 & 1 & 1 & 1 & 1 & 1 & 1 \\
\hline
\end{tabular}

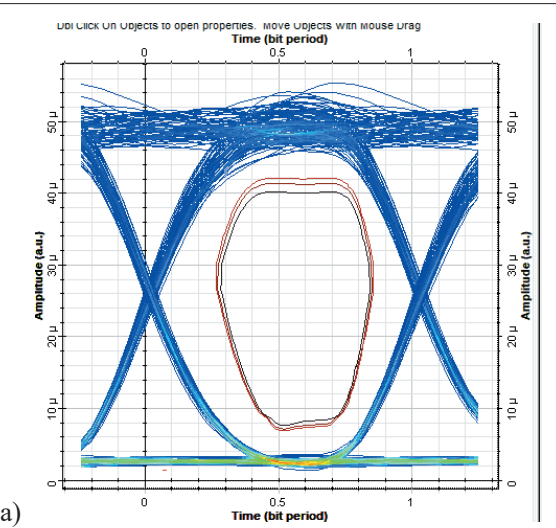

a)

Fig. 6. Eye diagram of the received signal for the FSO link distance $\mathrm{L}=2000 \mathrm{~m}$ and attenuation caused by: a) moderate rain, b) moderate fog.

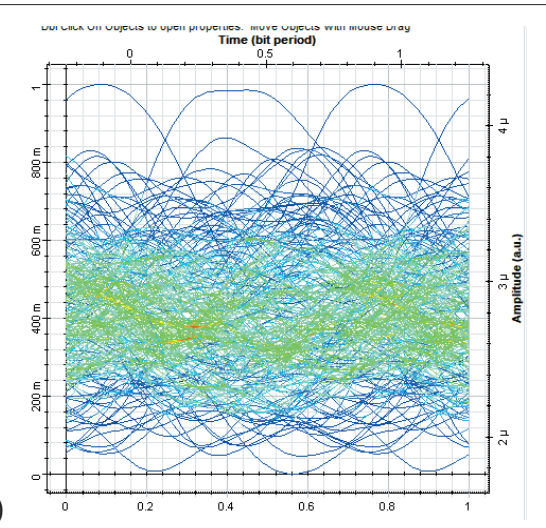

b) 
Fig. 7 and Fig. 8 show a comparison of the signal spectrum before transmission and after transmission through the FSO channel at attenuation caused by light haze and light fog for link distances of $1000 \mathrm{~m}$ and $2000 \mathrm{~m}$, respectively.

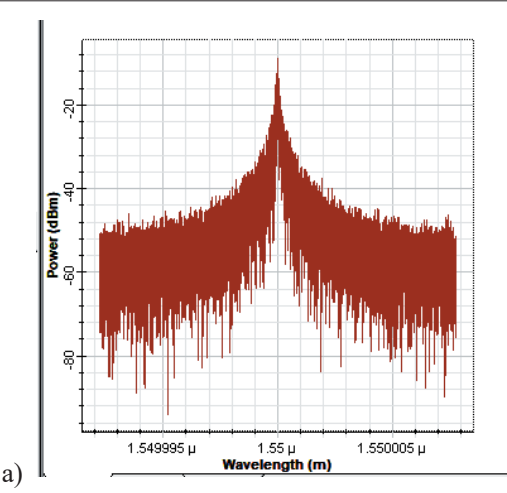

b)
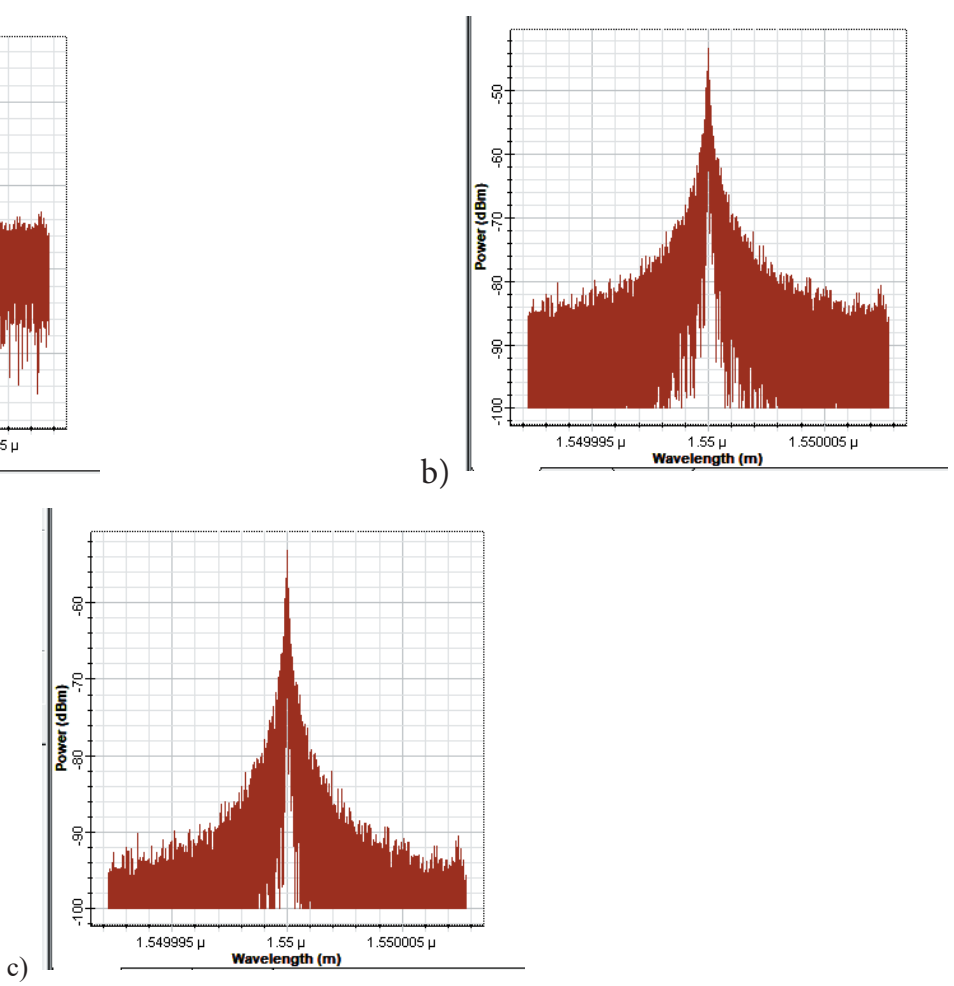

Fig. 7. Signal spectrum: a) before transmission, b) after transmission through FSO channel at $1000 \mathrm{~m}$ in light haze, c) after transmission through FSO channel at $1000 \mathrm{~m}$ in light fog.

a)

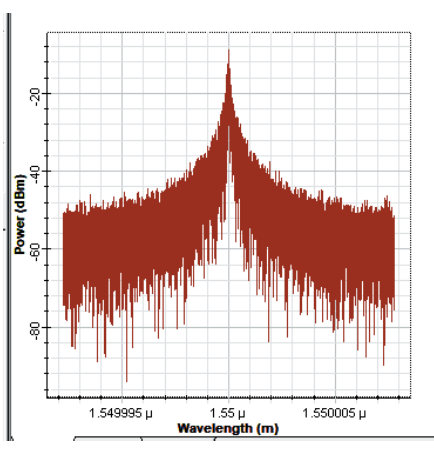

b)

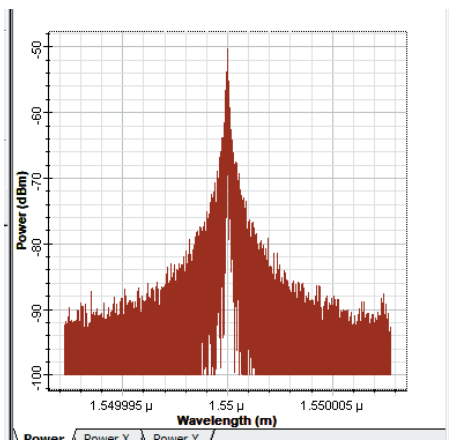

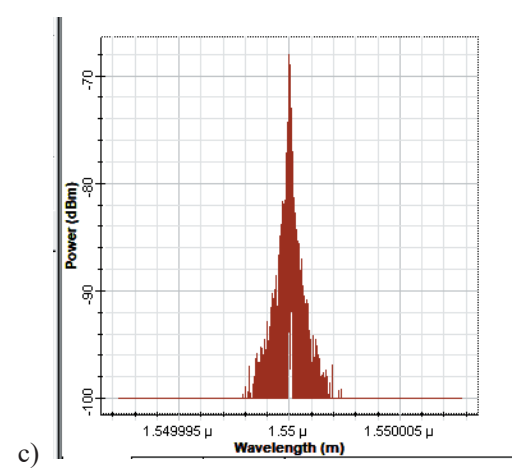

Fig. 8. Signal spectrum: a) before transmission, b) after transmission through FSO channel at $2000 \mathrm{~m}$ in light haze, c) after transmission through FSO channel at $2000 \mathrm{~m}$ in light fog. 


\section{CONCLUSION}

By simulating the FSO system operating at wavelengths of $850 \mathrm{~nm}, 1315 \mathrm{~nm}$ and $1550 \mathrm{~nm}$, the impact of different levels of atmospheric turbulence and link distance on the transmission quality using the BER parameter and $\mathrm{Q}$ factor is shown. The simulation results confirm the analytical results presented in the literature in terms of achieving transmission quality at different lengths of the transmission FSO link operating in different atmospheric phenomena. The FSO system has the best performance in the $3 \mathrm{rd}$ optical window $(1550 \mathrm{~nm})$, where it is possible to achieve quality transmission over long distances in almost all weather conditions. The decrease in the $\mathrm{Q}$ factor is significantly more pronounced at shorter FSO link lengths.

\section{REFERENCES}

[1] O. Hasan and M. Taha, "Optimized FSO System Performance over Atmospheric Turbulence Channels with Pointing Error and Weather Conditions," Radioengineering, vol. 25, no. 4, pp. 658-665, 2016. DOI: $10.13164 /$ re.2016.0658.

[2] A. K. Majumdar, Advanced Free Space Optics (FSO). New York: Springer-Verlag, 2015.

[3] I. K. Son and S. Mao, "A Survey of Free Space Optical Networks," in Digital Communications and Networks, vol. 3, no. 2, pp. 67-77, 2016. DOI: 10.1016/j. dcan.2016.11.002.

[4] S. Arnon, J. Barry, G. K. Karagiannidis, R. Schober, and M. Uysal, Advanced Optical Wireless Communication Systems. Cambridge: Cambridge University Press, 2012.

[5] M. A. Khalighi and M. Uysal, "Survey on Free Space Optical Communication: A Communication Theory Perspective," IEEE Communications Surveys \& Tutorials, vol. 16, no. 4, pp. 2231-2258, 2014. DOI: 10.1109/comst.2014.2329501.

[6] G. K. Varotsos, H. E. Nistazakis, Ch. K. Volos, and G.S. Tombras, "FSO Links with Diversity Pointing Errors and Temporal Broadening of the Pulses over Weak to Strong Atmospheric Turbulence Channels," Optik - International Journal for Light and Electron Optics, vol. 127, no. 6, pp. 3402-3409, 2016.

[7] H. A. Fadhil, A. Amphawan, H. A. B. Shamsuddin, T. H. Abd, H. M.R. Al-Khafaji, S. A. Aljunid, and N. Ahmed, "Optimization of Free Space Optics Parameters: An Optimum Solution for Bad Weather Conditions," in Optik - International Journal for Light and Electron Optics, vol. 124, no. 19, pp. 3969-3973, 2013. DOI: 10.1016/j.ijleo.2012.11.059.
[8] S. N. Zainurin, I. Ismail, U. S. Saulaiman, W. Z. W. Ismail, F. H. Mustafa, M. Sahrim, J. Jamaluddin, and S. R. Balakrishnan, "A Study on Malaysia Atmospheric Effect on Radio over Free Space Optic through Radio Frequency Signal and Light Propagation in Fiber for Future Communication Development," Proceeding of The 2nd International Conference on Applied Photonics and Electronics 2019 (InCAPE 2019), 2020. DOI:10.1063/1.5142110.

[9] L. C. Andrews and R. L. Phillips, Laser Beam Propagation through Random Media. 2nd ed. Bellingham: SPIE Press, 2005.

[10] H. E. Nistazakis, T. A. Tsiftsis, and G. S. Tombras, "Performance Analysis of Free-Space Optical Communication Systems over Atmospheric Turbulence Channels," IET Communications, vol. 3, no. 8, pp. 1402-1409, 2009. DOI: 10.1049/iet-com.2008.0212.

[11] G. Ritu and S. Preeti, "Performance Analysis of FSO System for Different Fog Conditions," Proceeding of International Conference on Intelligent Communication, Control and Devices, Advances in Intelligent Systems and Computing, pp. 181-187, 2017. DOI: 10.1007/978-981-10-1708-7_20.

[12] M. B. El Mashade and A. H. Toeima, "Performance Characterization of Spatial Diversity based Optical Wireless Communication over Atmospheric Turbulence Channels," Radioelectronics and Communications Systems, vol. 61, no. 4, pp. 135-152, 2018. DOI: $10.3103 /$ S0735272718040015.

[13] S. Malik and P. K. Sahu, "Performance Analysis of Free Space Optical Communication System Using Different Modulation Schemes over Weak to Strong Atmospheric Turbulence Channels," Optical and Wireless Technologies, pp. 387-399, 2019. DOI: 10.1007/978-981-13-6159-3_41.

[14] A. A. Farid and S. Hranilovic, "Outage Capacity Optimization for Free-Space Optical Links with Pointing Errors," Journal of Lightwave Technology, vol. 25 , no. 7 , pp. 1702-1710, 2007. DOI: $10.1109 /$ JLT.2007.899174.

[15] R. de S. C. Bessoni, L. F. S. e Silva, V. G. A. Carneiro, and M. T. M. R. Giraldi, "A Comparison of Different Modeling Approximations for a FSO Channel with Radial Displacement," Proceeding of 2015 SBMO/IEEE MTT-S International Microwave and Optoelectronics Conference (IMOC), 2015. DOI: 10.1109/imoc.2015.7369167.

[16] OptiSystem web-site: https://optiwave.com/optisystem-overview 